\title{
Análise de conteúdos: Uma abordagem qualitativa sobre instruções visuais em bulas de medicamentos
}

\author{
Analysis of contents: A qualitative approach on the visual instructions of medicine \\ leaflets
}

Luiz Gustavo Amorim Lopes; Carla Galvão Spinillo.

\begin{abstract}
Medicamento, Instruções Visuais, Análise de Conteúdo
O propósito deste artigo é analisar o conteúdo das instruções visuais em bulas de medicamento a partir de uma abordagem qualitativa, de maneira a auxiliar no entendimento das instruções visuais aplicadas as bulas de medicamentos, afim de investigar como se desenvolve o levantamento de dados não numéricos e como realiza-se a análise dos conteúdos coletados, por meio de entrevista semiestruturada. De tal modo o presente artigo divide-se nos seguintes tópicos: (1) introdução; (2) pesquisa qualitativa através de análise de conteúdo, com a explicação da abordagem de pesquisa, (3) A contextualização do problema e do objetivo de pesquisa em que queira se desenvolver seus resultados; (4) método, com o detalhamento dos participantes e o material da coleta dos dados; (5) resultados da pesquisa com a discussão da coleta e a sua relação com o método de análise de conteúdo.
\end{abstract}

\section{Medication, Visual Instruction, Content Analysis}

The purpose of this paper is to analyze the contents of the visual instructional in the medicinal package inserts, from a qualitative approach in order to assist in the insight of the visual instructions applied to the medication leaflet. The study of investigate development the information no numerical as analysis of the contents collected, through a semi-structured interview. Therefore, the present article divides in the following topics: (1) introduction; (2) qualitative research through content analysis, with the explanation of the research approach, (3) the contextualization of the problem and the research objective in which it wants to develop its results; (4) method, with the details of the participants and the material of data collection; (5) search results with the collection discussion and its relationship to the content analysis method.

\section{Introdução}

A elaboração de uma pesquisa científica parte inicialmente de um pressuposto levantado por seu próprio idealizador, ou seja, o pesquisador e/ou estudante, com relação ao assunto ou tema que busca abordar, levanta uma hipótese nitidamente especificada e as variáveis operacionais delimitadas.

Segundo Godoy (1996, p. 58), a expressão "ciências sociais" é utilizada para indicar diferentes áreas do conhecimento que se preocupam com os fenômenos sociais, dentre eles: aspectos econômicos, políticos, psicológicos, culturais e educacionais, dos quais são responsáveis pela junção do caráter humano e social.

Em relação a abordagem qualitativa, Godoy (1996, p. 58), afirma que pesquisas realizadas no campo das ciências sociais são valorizadas apenas no campo quantitativo, por descrever e explicar um determinado fenômeno, ou seja, possibilitando a aplicação em diferentes maneiras para verificar o fenômeno, recurso constantemente utilizada por antropólogos e sociólogos. Entretanto, a abordagem qualitativa vem ganhando destaque nos últimos trintas anos, de modo que a sua aplicação tem ocorrido em diversas áreas do conhecimento (GODOY, 1996).

As etapas de mensuração dos dados coletados, assim como a sua avaliação, devem ser realizadas de modo que se possa evitar conteúdos e informações distorcidas, para que não venha a comprometer a etapa de análise e interpretação, tornando uma margem de segurança aos resultados coletados (GODOY, 1996).

Anais do 8 CIDI e 8 CONGIC

Guilherme Santa Rosa; Cristina Portugal (orgs.)

Sociedade Brasileira de Design da Informação - SBDI

Natal | Brasil | 2017

ISBN 978-85-212-1305-5
Proceedings of the $8^{\text {th }} \mathrm{CIDI}$ and $8^{\text {th }}$ CONGIC

Guilherme Santa Rosa; Cristina Portugal (orgs.)

Sociedade Brasileira de Design da Informação - SBDI

Natal| Brazil | 2017

ISBN 978-85-212-1305-5 
Os resultados não necessitam de métodos estatísticos, já que em uma pesquisa qualitativa, não se busca enumerar e/ou medir o fato avaliado, faz-se apenas uma descrição das informações coletadas, sejam elas obtidos com pessoas, lugares ou processos interativos realizados entre o pesquisador e o participante, por meio da compreensão de um fenômeno, a partir da sua observação (GODOY, 1996).

Contudo, a análise de conteúdo não possui pretensão de desenvolver um overview da técnica de análise do conteúdo como procedimento, mas a descrição acerca do método utilizado, distinguindo as contribuições relacionadas as técnicas utilizadas para a análise dos dados no âmbito da pesquisa e as definições de estratégias para o seu desenvolvimento (MOZZATO, 2011).

Após essa caracterização da pesquisa cientifica, passa-se a delimitar neste artigo quais os problemas e objetivos da pesquisa. O tema que se aplica e destina a abordagem qualitativa e a análise de conteúdo com instruções visuais, para realizar o preparo da Amoxicilina, instruções e ilustrações desenvolvidas pelos alunos do curso de Design Gráfico da Universidade Federal do Paraná, obtidos com os dados levantados por meio de questionário semiestruturado. Assim, os resultados levantados com este artigo, têm como objetivo realizar o detalhamento do método de análise de conteúdo, aplicado a um problema de pesquisa, a fim de gerar resultados e discussões por meio de uma abordagem qualitativa.

\section{Pesquisa qualitativa por meio da análise de conteúdo}

Para Godoy (1995) a pesquisa qualitativa como método de pesquisa, ocupa lugar entre os demais métodos, cujo objetivo é estudar um determinado fenômeno, que vem a envolver pessoas em suas relações sociais, aplicado aos mais variados ambientes. Segundo Neves (1996), a pesquisa qualitativa adquire diferentes significados à ciência social, o autor delimita que esta "compreende um conjunto de diferentes técnicas interpretativas que visam descrever e a decodificar os componentes de um sistema complexo de significados", cujo objetivo é expressar o fenômeno.

Esse tipo de abordagem possui algumas características básicas para compor o estudo qualitativo, buscando realizar uma análise de maneira integrada para compreender o contexto no qual ocorrem e a parte que o pertencem. Assim sendo, o pesquisador busca captar o fenômeno através da pesquisa de campo, por meio das perspectivas das pessoas que estão envolvidas, coletando vários tipos de dados relevantes para que se possa compreender a dinâmica do fenômeno (GODOY, 1995).

Para Campos (2004, p. 611) a investigação para a realizar uma pesquisa de cunho cientifica, acarreta diferentes dificuldades, sejam estas nas etapas da pesquisa ou durante a execução. Esses problemas são muitas vezes associados ao desconhecimento ou a familiaridade com o método ou técnicas empregadas na pesquisa, de modo que nos procedimentos utilizados na pesquisa, possam surgir algumas variações que seja capaz de atender os objetivos da pesquisa (OLIVEIRA, 2008).

A análise do conteúdo pode ser definida segundo a visão de dois autores, o primeiro Berelson (1984, p.18) delimita como sendo uma "técnica de pesquisa que visa uma descrição do conteúdo manifesto de comunicação de maneira objetiva, sistemática e quantitativa". Entretanto Campos (2004) apresenta uma crítica a Berelson (1984), ou seja, de que tal análise esta relacionada a um levantamento do conteúdo e do objeto de análise. Por outro lado, para Bardin (1977), a análise de conteúdo apresenta-se como sendo:

Um conjunto de técnicas de análise das comunicações, visando obter um procedimentos objetivos e sistemáticos de descrição do conteúdo das mensagens, indicadores (quantitativos ou não) que permitam a inferência de conhecimentos relativos as condições de produção/recepção destas mensagens (BARDIN, 1977, p.42).

Segundo Dellagnelo e Silva (2005), a análise do conteúdo está em constante crescimento no Brasil, principalmente através da abordagem qualitativa. Para que venha a possuir uma validade de reflexão acerca da técnica relacionada, Mozzato (2011) aponta para que qualquer técnica de análise de dados, constitui-se em uma metodologia de 
interpretação, por meio dos procedimentos típicos de levantamento de dados. Creswell (2007, p.194) descreve o processo de análise como um recurso que "consiste em extrair o sentido dos dados de texto e imagem".

Para Chirzzotti (2006) descreve o procedimento para a análise de dados como:

A descodificação de um documento pode utilizar-se de diferentes procedimentos para alcançar o significado profundo das comunicações nele cifradas. A escolha do procedimento mais adequado depende do material a ser analisado, dos objetivos da pesquisa e da posição ideológica e social do analisador (CHIRZZOTTI, 2006, p. 98).

Oliveira (2008) afirma que a análise de conteúdo é um instrumento de pesquisa com diversas formas de aplicação, contudo para atingir tais objetivos, o procedimento pode sofrer variações, conforme as funções da pesquisa. Entretanto, Duarte (2002, p. 140) ressalta que mesmo que a abordagem da pesquisa qualitativa possua alguns riscos e dificuldades, acaba mostrando-se intensamente estimulante, agradável e desafiadora para o pesquisador. Oliveira (2008) ainda aponta para quatro categorias empíricas, com o objetivo de realizar uma boa análise de conteúdo, configuradas em:

- Homogeneidade: não confundir coisas semelhantes;

- Exaustividade: esgotar por completo os textos;

- Exclusividade: não classificar o objeto a duas categorias distintas;

- Objetividade: diferentes maneiras para se alcançar o objetivo principal da pesquisa.

Além disso, Oliveira (2008) faz uma segunda classificação para o conjunto de categorias considerando também a relevância dos temas pesquisados na abordagem quantitativa e qualitativa, o primeiro destinado à quantidade de unidade de registro, assim como o conjunto de análise, e, para a segunda a forma de compor uma pesquisa, como o desenvolvimento de respostas, para as seguintes questões:

- o tema é fundamental para compreender o objeto de estudo?

- o tema revela alguma faceta do objeto de estudo que interessa o pesquisador?

- o tema desvela alguma dimensão do referencial teórico adotado?

Portanto, sintetizar essas categorias empíricas aplicadas ao texto, demonstra as características em relação aos termos (OLIVEIRA, 2008). Desta maneira, levantam-se os resultados alcançados por meio dos textos, além de acrescentar significados assim como são especificados na composição de grande parte do material a ser analisado.

\section{A Priori: contextualização do problema e objetivo da pesquisa.}

A Constituição Federal de 1988 delimita, no artigo 196, que "A saúde é um direito de todos e dever do estado" (BRASIL, 2006). Entretanto, nesta área encontram-se as maiores dificuldades no âmbito nacional, principalmente para a Farmacoterapia ${ }^{1}$, em que o paciente/usuário faz o preparo e a utilização da própria medicação. Paracelsus (1493-1541), afirma que "todas as substâncias são venenos, não há uma que não seja veneno. A posologia correta diferencia o veneno do remédio" (KLAASSEN, 1985, p. 1047).

Baseado na afirmação de Dirceu Raposo de Mello, Diretor-Presidente da Agência Nacional de Vigilância Sanitária (ANVISA) - órgão que regulariza e fiscaliza toda a medicação comercializada no país, "o medicamento, se utilizado de forma inadequada, pode causar mais danos do que benefícios", ou seja, o uso indevido, pode acabar ocasionando dependências, reações alérgicas e até mesmo a morte do paciente em alguns casos, sendo assim, pode ser considerada como um problema de saúde pública, não apenas no âmbito nacional, mas também no âmbito mundial (ANVISA, 2007).

\footnotetext{
${ }^{1}$ Aplicação dos medicamentos na prevenção ou tratamento de doenças (ANVISA, 2017).
} 


\section{CIDI 2017

O Sistema Nacional de Informações Tóxico-Farmacológicas (SINITOX), apresentado do ano 2003, afirma que a intoxicação por medicamentos é responsável por $28,2 \%$ dos casos no país. Isto é, em relação aos fármacos classificados como: analgésicos, antitérmicos e anti-inflamatórios, de uso livre da população e que podem ser adquiridos sem a necessidade da receita médica, assim o usuário/paciente, fica ausente das recomendações ou prescrições de algum profissional da saúde (ANVISA, 2007).

Destacamos a importância da bula de medicamento, como sendo o único documento que acompanha a medicação, após a compra deste, com todas as informações necessárias acerca do medicamento, de como solucionar possíveis dúvidas relacionadas ao procedimento ou a utilização, seja por meio de textos ou imagens. Spinillo (2007) aponta a importância da mensagem visual, destinadas às pessoas analfabetas ou com baixos níveis de escolaridade. Nessa abordagem Horn (1998) delimita "a integração de palavras, imagens, e formas em uma única unidade de comunicação" como linguagem visual.

Esta pesquisa delimita como Priori, o entendimento que os usuários e/ou pacientes tem com informações representadas por meio de imagens e textos nas bulas de medicamentos, de modo que para alcançar tais objetivos, realiza-se a exploração por entrevistas semiestruturadas, composta por questões abertas - com a finalidade de verificar a opinião dos participantes, de modo a obter dados de forma qualitativa, por meio da análise de conteúdos - e, também por questões fechadas, por meio de perguntas com respostas já determinadas durante o desenvolvimento da própria entrevista pelo pesquisador.

\section{Método}

O método abordado nesta pesquisa busca verificar o entendimento da mensagem passada para os participantes por meio das instruções visuais. O material utilizado no estudo foi composto pelos alunos da Universidade Federal do Paraná (UFPR), como trabalho à disciplina de Design da Informação no ano de 2013, sendo utilizado este mesmo material para a coleta dos dados, sendo apresentados para 10 (dez) participantes de ambos os sexos, das mais variadas idades e níveis de escolaridade, além disso, foi estabelecido um único critério de estas possuíssem idade igual ou superior a 18 (dezoito) anos e que participassem de forma voluntária. Assim para as entrevistas semiestruturada compostas por questões fechadas com repostas pré-determinada e aberta com perguntas livres aos participantes como propor sugestões ou realizar o detalhamento da questão. A seguir apresentaremos os resultados obtidos com o estudo.

\section{Composição do material instrucional}

A proposta do material utilizado, do qual foram desenvolvidos pelos alunos do curso de Design Gráfico da Universidade Federal do Paraná, como instrumento avaliativo para a disciplina de Design da informação, ministrada pela Prof ${ }^{a} \mathrm{PhD}$. Carla Galvão Spinillo, o conteúdo abordado pelo material instrucional, apresenta o preparo manuseio e aplicação da medicação,

Amoxicilina, utilizada com frequências em crianças para a aplicação por via oral. Baseado na própria bula de medicamentos os alunos desenvolveram as ilustrações instrucionais do material gráfico, apresentando as seguintes dimensões reais: Aberto com as medidas totais de 49,5 por $9,5 \mathrm{~cm}$ (Figura 1) e Fechado com 17,5 por 9,5 cm (Figura 2), entretanto o material gráfico instrucional não é apenas composto por imagens para o entendimento de seu conteúdo, mas é complementado com a utilizar de pequenos textos (Figura 3), com o objetivo de auxiliar o paciente no entendimento da instrução para o preparo da medicação Amoxicilina.

Figura 1: Material gráfico - Completo. Ilustração de Lucas Zeferino e Ueliton Pires (Livre dos direitos autorais).
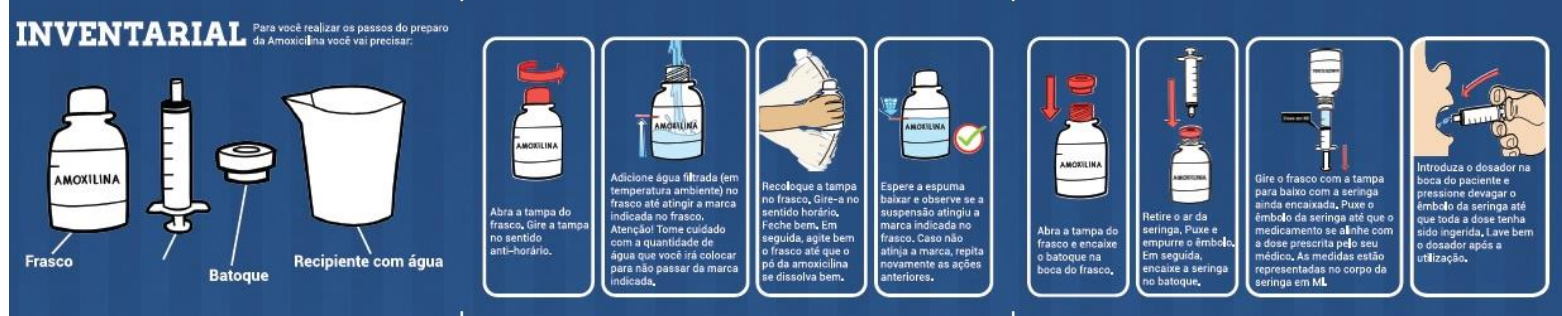

Anais do 8ํㅡㄹ Congresso Internacional de Design da Informação | CIDI 2017

Proceedings of the $8^{\text {th }}$ Information Design International Conference | CIDI 2017 


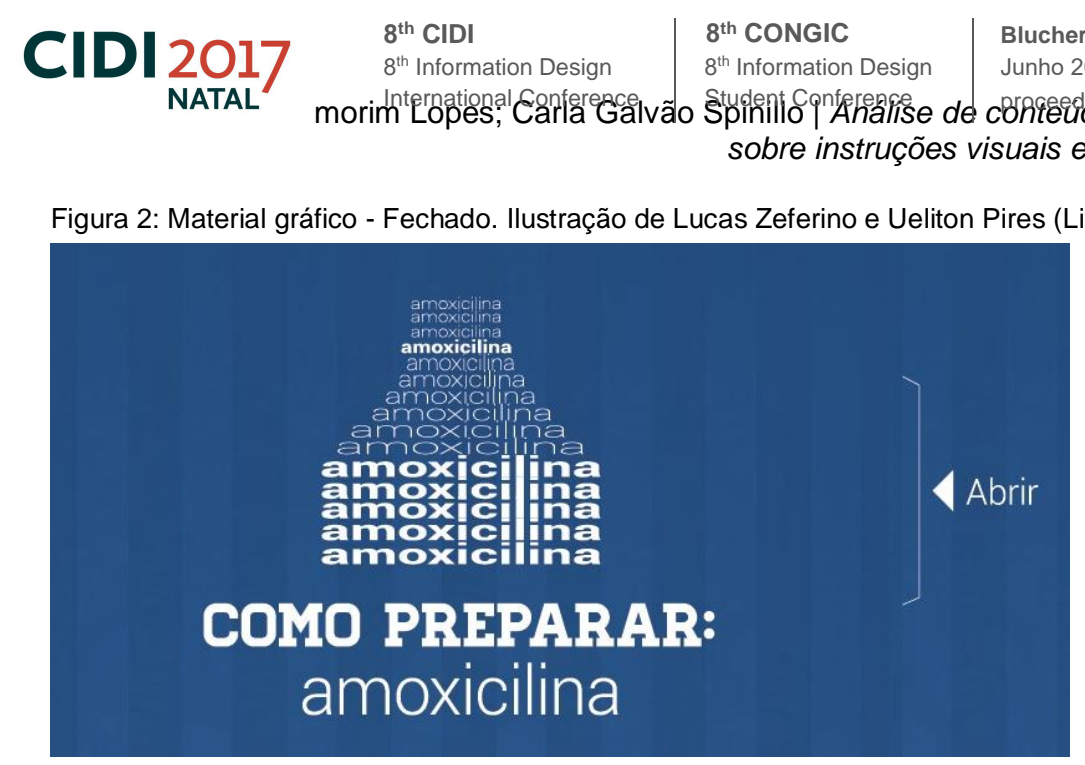

Figura 3: Conteúdo textos e imagens Ilustração de Lucas Zeferino e Ueliton Pires (Livre dos direitos autorais).

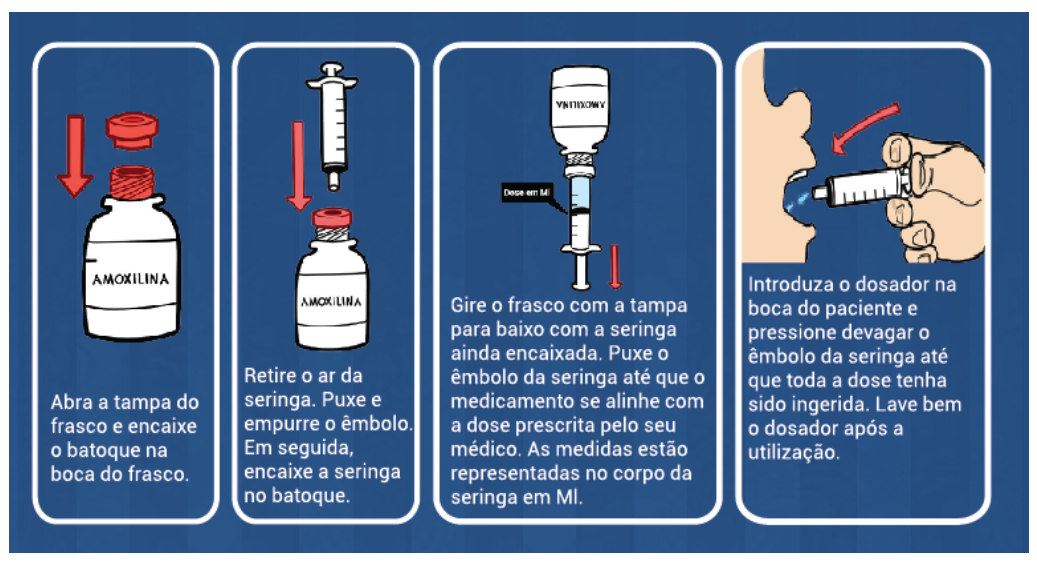

\section{Seleção dos participantes}

Duarte (2002) destaca que no período da realização de uma pesquisa, algumas questões são apresentadas inicialmente enquanto outras vão aparecendo no decorrer da investigação, para as questões levantadas necessitam que o pesquisador faça um trabalho de reflexão a respeito desses novos dados coletados, de modo a relacionar em torno do problema encarado, com os erros cometidos, as escolhas feitas e as dificuldades descobertas.

A seleção dos participantes em uma pesquisa cientifica é primordial, já que pode interferir diretamente na qualidade dos dados obtidos, em que o pesquisador fará a compreensão de maneira mais ampla do problema delimitado na pesquisa (DUARTE, 2002).

Segundo Durhan (1986) apresenta algumas armadilhas, que possam surgir de modo a comprometer os dados levantados com as pesquisas, através dos questionários e entrevista, alertando para problemas que podem surgir especialmente quanto o entrevistador e o entrevistado compartilham da mesma natureza de dificuldades.

Assim este estudo que busca ser investigados, é composto por pessoas com idade igual ou superior a 18 anos, não delimitando critérios para a seleção em relação à escolaridade ou sexo. Todos os participantes foram recrutados de maneira voluntária, que após a explicação aceitassem participar da pesquisa, delimitando apenas para pessoas com residência na cidade de Curitiba-PR.

Delimitou-se como requisito para a aplicação da entrevista semiestruturada, é que o pesquisador não poderia interagir com entrevistado de modo a não influenciar no posicionamento das respostas dos participantes. O pesquisador era permitido apenas suprir possíveis dúvidas relacionadas ao entendimento das questões, para esse levantamento delimitou-se o número de 10 (dez) participantes para a sua aplicação. 


\section{CIDI 2017}

\section{Entrevista semiestruturada}

A entrevista semiestruturada delimitada por Queiroz (1988) como uma técnica de levantamento de dados, realizada no formato de conversação continua entre o entrevistado e o pesquisador, dirigidos de acordo com os objetivos da pesquisa.

Para Duarte (2002) a entrevista semiestruturada e a melhor maneira de se formular perguntas, sendo capaz de ponderar o nível de resposta em uma determina questão, em que o pesquisador possa evitar ao máximo gesto de aprovação desconfiança, rejeição, dúvidas e entre outras formas, para as questões da pesquisa.

De modo que o roteiro de uma entrevista é importante para que se possa auxilia o pesquisador. Duarte (2002) descreve que as perguntas que necessitam explicação para os participantes, como forma de sanar possíveis dúvidas, assim estes tipos de pergunta devem ser retiradas do roteiro de entrevista, de modo que a realização de várias explicações poderá induzir de alguma maneira ou outra sugestão de repostas para os participantes.

O questionário que compõem a entrevista semiestruturada, proposto nesse estudo possui 16 questões, entre abertas e fechadas, a primeira destina-se para que os participantes possam expor suas opiniões e sugestões sobre o conteúdo verificado e em segundo com questões fechadas com respostas pré-definidas. Algumas questões fechadas, com objetivo de levantar o detalhamento melhor das questões fechadas, destacando para as informações relevantes para a pesquisa e não apenas os resultados gerados com as perguntas.

Figura 4: Questões fechadas e com indagação do por quê?

6. Em sua opinião, instruções visuais/imagens sobre como usar medicamentos:
Atrapalham a compreensão [1]
[2]
[3]
[4]
[5] Auxiliam a compreensão

Por quê?

Contudo, dentre as 16 questões que compõem o questionário apenas uma pergunta se estabeleceu totalmente aberta (Figura 5), em que os participantes apresentaram de maneira livre a sua opinião em relação ao material gráfico apresentado, destacando como a única questão que se aplica a abordagem qualitativa, não ocorrendo nenhuma condição que houvesse a limitação de suas repostas.

Figura 5: Questões Aberta

16. Em sua opinião, o que poderia ser melhorado neste material para ensinar como preparar e/ou usar o medicamento?

\section{Resultado da entrevista Semiestruturada}

Duarte (2002) aponta para algumas críticas por conta da sociologia que surge com relação aos relatos orais, de modo que, a forma de colher, transcrever e interpretar os dados, configurados como uma "garantia de confiabilidade", por outro lado alguns estudos demonstram que a viabilidade de propor alguns critérios para se realizar a sua avaliação, baseia-se nos procedimentos de investigação, assim como os dados também alcançados de maneira qualitativos sendo densos e complexos para serem analisados. 


\section{CIDI 2017

Assim, para pesquisas com dados não numéricos (e.g texto), necessita desenvolver a codificação por meio da relação de frases, palavras e/ou expressões (DUARTE, 2002). De tal modo, mostra-se após os resultados analíticos, compete ao pesquisador se aprofundar nos resultados alcançados, mas que também seja capaz de consultar a literatura, como forma de verificar o problema e o objetivo que motivou a realização da investigação.

Campos (2004) afirma que a que análise temática são recortes do próprio texto, realizando com isso um processo dinâmico e indutivo, a fim de produzindo uma mensagem concreta explícita, ou com significados não aparente nos textos, delimitando com clareza a motivação da escolha, não levando em consideração o material pesquisado.

Entretanto para Duarte (2002, p. 152) os objetivos alcançados e suas explicações para tais resultados vão depender do grau em que o pesquisador possa realizar entre o seu micro assunto investigado, com o macro delimitando como uma forma mais abrangente a pesquisa.

Os resultados detalhados posicionam-se apenas com relação às questões apresentadas anteriormente (Entrevista semiestruturada) não apresentando os resultados completo da pesquisa, já que não é o objetivo desse artigo. Contudo a estudo busca apenas a abordagem do questionário semiestruturado, para a realização da descrição das etapas compostas por: delimitação dos participantes, questões aplicadas aos participantes e análise dos dados coletados.

Após o levantamento com os 10 participantes com a tabulação dos dados buscamse agrupar os resultados, tornando explicitas as respostas semelhantes e também as divergentes. Optou-se pela apresentação da soma dos resultados por gráficos de barras (Figura 6 e 7), estabelecendo as respostas ao lado direito e a quantidade de participante na parte inferior do gráfico, para detalhar os resultados.

Figura 6: Resultados: Questão fechada - Em sua opinião, instruções visuais/imagens sobre como usar medicamentos.

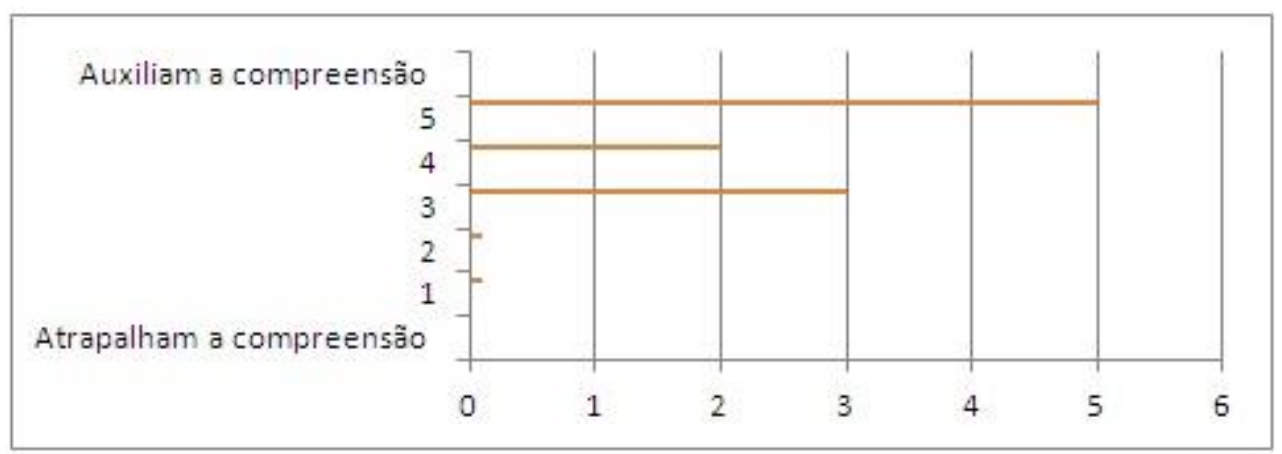

Figura 7: Resultados: Questão fechada/aberta.

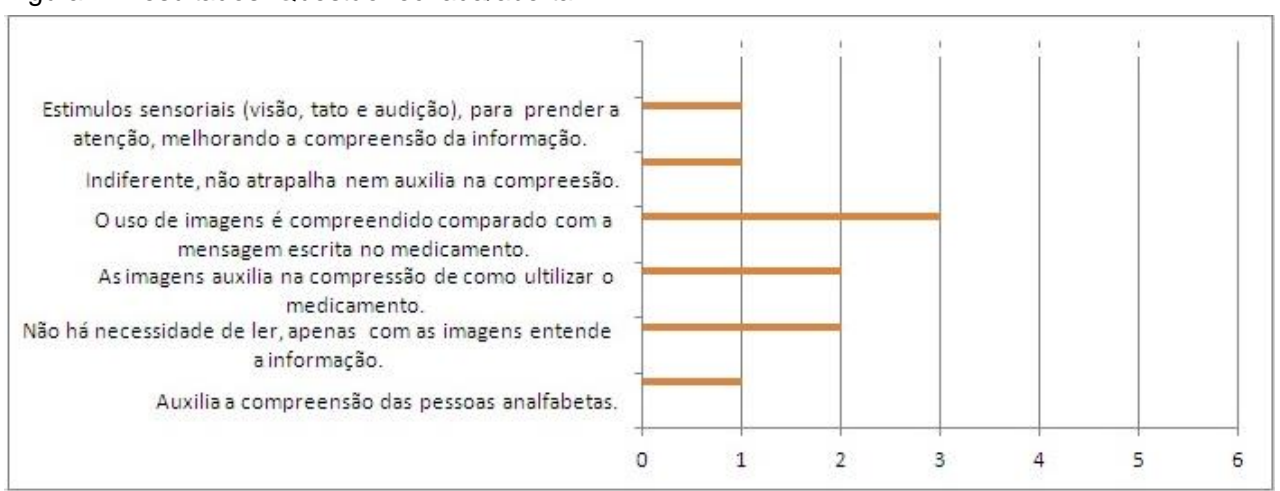

A mensuração dos dados obtidos com esta primeira pergunta, faz o agrupamento dos textos, delimitando o real significado das frases levantadas e incorporar as repostas semelhantes. Alcançou os maiores resultados para a reposta "o uso da imagem é compreendido comparado com a mensagem escrita no medicamento" opção de escolha de 


\section{CIDI 2017}

três entre dez pessoas que responderam a entrevista, desenvolvendo resultados de forma mais generalista, semelhante a outras questões, que possuía o mesmo significado.

Nas questões abertas que levantam as opiniões dos participantes, alcançou o maior número de respostas, resultado diferentes para as questões com a abordagem do por quê, abordadas juntos as questões fechadas na maioria do questionário. Contudo as perguntas abertas aplicam-se com respostas em formato livre pelos participantes, destacando para as semelhanças entre respostas o posicionando de cinco dos dez participantes entrevistados "considerou o material instrucional visual bom ou ótimo para o preparo da medicação" (Figura 8), assim a nomenclatura "boa" como "ótima", configurando como a qualidade do material, considerando como parecidas essas afirmações e com isso realizando o seu agrupamento, entretanto podemos algumas respostas forma obtidas isoladamente, ou seja, não podendo ser associada a outros resultados semelhantes.

Figura 8: Resultado: Questões Aberta.

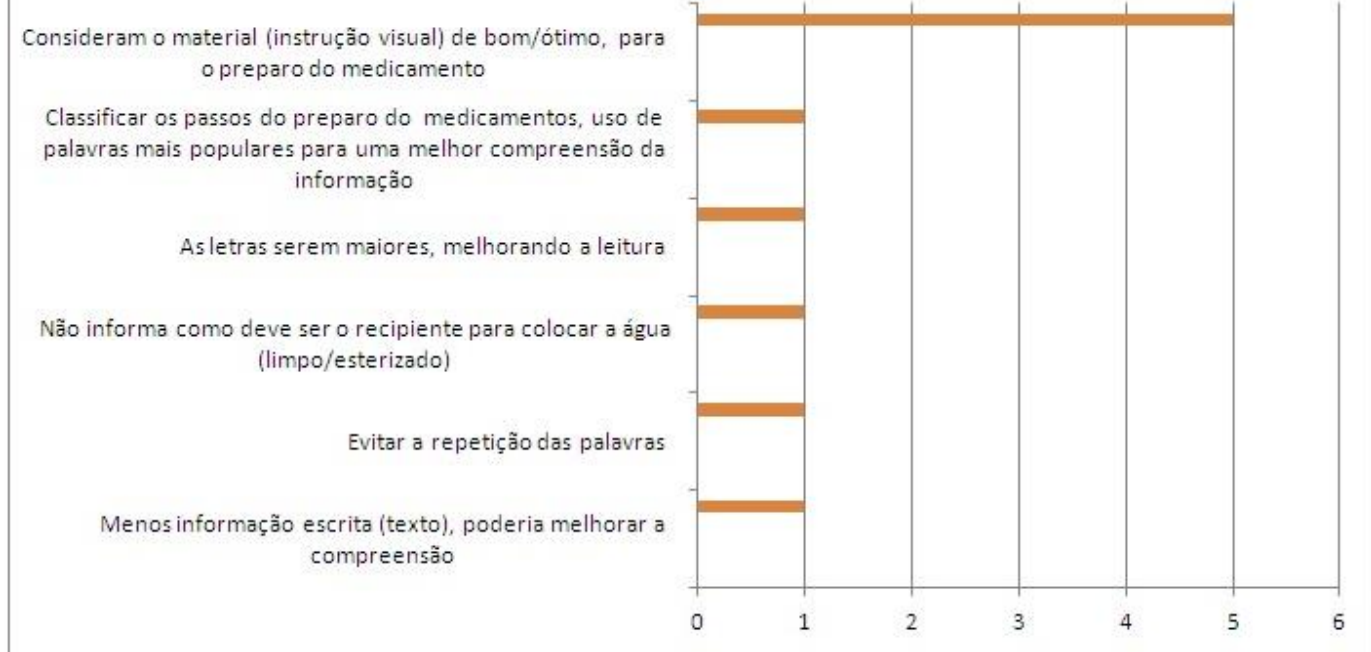

\section{Considerações finais}

A metodologia aborda para análise de conhecimento, faz a sua classificação de maneira bem abrangente, destacando para as diferentes abordagens (qualitativa e quantitativa), e a variação dos procedimentos e técnicas para a coleta dos dados. O presente estudo teve como objetivo apenas delimitar a entrevista por meio de questionários, destacando para a forma de se realizar a sua coleta dos dados e a mensuração de tais resultados obtidos com os participantes. Assim a fase de elaboração das perguntas e montagem do roteiro, passa a ser de extremamente importância, como fator principal para se alcançar os objetivos da pesquisa.

A abordagem para a análise dos resultados aplica-se de modo qualitativa, por realizar a busca do entendimento dos participantes em relação ao material apresentado (Figura 1), a fim de levantar opiniões e/ou explicações para as opções de repostas (com a utilização do por quê?).

O tratamento dos resultados alcançados para a análise de conteúdo é destinado aos mais variados tipos de técnicas e/ou procedimentos, contudo a verificação para a análise dos resultados faz o uso das informações que são levantadas pelo próprio pesquisador e/ou responsável pela pesquisa, destacando como o levantamento da literatura, com outros estudos semelhantes relacionados à pesquisa atual, para alcançar os objetivos propostos com a coleta dos dados.

Os resultados alcançados com a coleta dos dados, seja por meio das questões abertas ou fechadas, mostraram-se bem semelhantes, para as perguntas abertas permitindo o agrupamento dos resultados alcançados, contudo para as outras questões apresentam resultados totalmente isolados, não realizando a junção dos dados semelhantes. 
Para a última questão abordada pelo modelo, apresentam-se totalmente aberta levantando indagações e/ou soluções que podem ser consideradas em estudos futuros, dos quais não foram observadas pelo próprio pesquisador, para a concepção do instrumento da coleta dos dados, informações que podem ser aplicados em outras pesquisas baseando-se nas respostas obtidas pelos participantes. Conclui-se que a análise de conteúdo exige um ardo trabalho de coleta e análise dos resultados, formado normalmente pelo próprio pesquisador. Ao fim do processo de coleta, podem ser obtidas informações bem relevantes ao estudo, assim como informações para o pesquisador, de modo a entender a fundo o problema verificado, por meio da abordagem qualitativa, possa verificar possíveis problemas dos quais não foram abordados ou relacionados ao estudo, delimitando temas e problemas para possíveis pesquisas futuras com tais resultados levantados.

\section{Agradecimento}

Agradecemos ao apoio financeiro proporcionado pela CAPES no desenvolvimento desse estudo, aos alunos de Graduação em Design gráfico da Universidade Federal do Paraná, Lucas Zeferino e Ueliton Pires por disponibilizar as ilustrações instrucionais para está investigação e a todos os participantes voluntários que contribuíram para o seu desenvolvimento.

\section{Referências}

ANVISA, 2007. Os perigos do uso inadequado de medicamentos. Disponível em: http://www.anvisa.gov.br/divulga/reportagens/060707.htm. Acesso:10/12/2015.

BARDIN, L. Análise de conteúdo. Lisboa: Edições 70; 1977.

BERELSON, B. Content analysis in communication research. New York: Hafner; 1984.

BRASIL. Coletânea de Normas para o Controle Social no Sistema Único de Saúde. Ministério da Saúde, Conselho Nacional de Saúde. 2. ed. Editora do Ministério da Saúde. Brasília, 2006. p. 1-7.

CAMPOS, C. J. G. Método de análise de conteúdo: ferramenta para a análise de dados qualitativos no campo da saúde. Rev Bras Enferm, v. 57, n. 5, p. 611-4, 2004.

CRIZZOTTI, A. Pesquisa em ciências humanas e sociais. 8를. Ed. São Paulo: Cortez. 2006.

CRESWELL, J. W. Projeto de pesquisa: métodos qualitativo, quantitativo e misto. $2^{\mathrm{a}}$ Ed. Porto Alegre: Artmed. 2007

DELLAGNELO, E. H. L., \& SILVA, R. C. Análise de conteúdo e sua aplicação em pesquisa na administração. Pesquisa qualitativa em administração: teoria e prática. São Paulo: FGV. 2005. P. 97-118.

DURHAN, E. R. A pesquisa antropológica com populações urbanas: problemas e perspectivas. A Aventura antropológica: teoria e pesquisa. Rio de Janeiro: Paz e Terra,1986. p. 17-38

GODOY; A. S. Pesquisa qualitativa: tipos fundamentais. Rev. Administração de Empresa. 1995, vol.35, n.3, pp. 20-29. ISSN 0034-7590. http://dx.doi.org/10.1590/S003475901995000300004 .

HORN, R. E. Visual language: Global communication for the 21st century. MacroVU, Incorporated, 1998.

KLAASSEN, C.D. Princípios de toxicologia. In: GILMAN, A.G.et al. Goodman e Gilman: as bases farmacológicas da terapêutica. 7. ed. Rio de Janeiro: Guanabara Koogan, 1985. p.1045-1052.

MOZZATO, A. R.; GRZYBOVSKI, D. Análise de conteúdo como técnica de análise de dados qualitativos no campo da administração: potencial e desafios. Revista de Administração Contemporânea, v. 15, n. 4, p. 731-747, 2011.

NEVES, J. L. Pesquisa qualitativa: características, usos e possibilidades. Caderno de pesquisas em administração, São Paulo, v. 1, n. 3, p. 2, 1996. 
OLIVEIRA, D. Cristina de. Análise de conteúdo temático-categorial: uma proposta de sistematização. Rev. enferm. UERJ, v. 16, n. 4, p. 569-576, 2008.

SPINILLO C.G; PADOVANI, S.; MIRANDA, F.; FUJITA, P. T. L. et al. Instruções visuais em bulas de medicamentos no Brasil: um estudo analítico sobre a representação pictórica da informação. In: 3ํㅡㄹ Congresso Internacional de Design da Informação, 2007, Curitiba.

\section{Sobre os autores}

Luiz Gustavo Amorim Lopes, Mestre em Design, Universidade Federal do Paraná (UFPR), Brasil, <gustavo.amorim.1904@gmail.com>.

Carla Galvão Spinillo; PhD em Design e Docente da Universidade Federal do Paraná (UFPR), Brazil <cgspin@gmail.com>. 